\title{
INFLUENCE OF THE NONLINEAR DYNAMIC BEHAVIOR OF JOURNAL BEARINGS ON GEAR-BEARING ASSEMBLIES
}

\author{
Sébastien Baguet \\ Philippe Velex \\ LaMCoS - INSA Lyon, France \\ sebastien.baguet@insa-lyon.fr
}

\begin{abstract}
Journal bearings cannot be considered as passive elements in gear-bearing assemblies, and the lubricant is recognized as playing an important role in the interactions between the shafts and the bearings. In order to take this influence into account, bearings are usually modeled by means of eight dynamic coefficients, i.e., asymmetric stiffness and damping matrices.

In this paper, a nonlinear approach is proposed enabling the behavior of a gear-shaft-bearing assembly to be analyzed. A discrete finite element model is used for the shafts, and a specific gear element is introduced which accounts for non-linear time-varying mesh stiffness as well as tooth shape deviations. The meshing forces are internal system forces whereas the effects of the bearings on the shafts are taken to be external. A combination of the Newmark time integration scheme and the Newton-Raphson algorithm is used to simultaneously solve the contact problem for the gear, and the Reynolds equations for the bearings. The resulting algorithm is applied to a single stage geared system with two shafts, four bearings, a pinion and a gear while taking mass unbalance, eccentricity and meshing excitations into account. Several examples are presented which demonstrate the influence of bearing nonlinearity and the efficiency of the proposed model and numerical procedure.
\end{abstract}

\section{INTRODUCTION}

The dynamic response of geared systems remains a major concern in terms of noise and vibration, especially in highspeed applications. In this context, journal bearings are recognized as interesting technological solutions since they provide significant stiffness and damping for reduced noise levels compared with rolling element bearings. The literature on journal bearings comprises numerous contributions, only a few of which can be cited here [1-7] and it is now accepted that, for most practical cases, the theoretical foundations are firmly established allowing accurate predictions of bearing performance. A survey about the theory of hydrodynamics and its applications to various bearing geometries and operating conditions can be found in the classic textbooks of Cameron [8], Pinkus and Sternlicht [9], Frêne et al. [10].

On the other hand, the simulation of gear dynamics has yielded a vast literature [11], [12] with the majority of the gear models based upon lumped parameter representations combining rigid gears, discrete elastic and dissipative elements [13], [14], [15] or, more recently, on combinations of shaft finite elements and elastic foundations [16]. Forcing terms are often derived from transmission errors (Gregory et al. [15], Munro [17], Özgüven and Houser [18]) and /or the contact conditions between the active flanks [19]. Non linear features in spur gearing such as backlash and shocks on tooth flanks have been analyzed by Kahraman and Singh [20], Kahraman and Blankenship [21], Parker et al. [22].

Over the last decade, computing procedures have been developed which include the characteristics of shafts, gears, bearings and housings in the prediction of the global vibrational behavior of a transmission [23-26]. The majority of these codes, however, are restricted to linear analysis, i.e., static solution and modal analysis, and bearing and gear models remain global. The present work contributes to the analysis of the interactions between gears, shafts and journal bearings in geared drives. In contrast to the majority of the models in the literature, the time-varying properties and non-linearities of bearings and gears are introduced in the simulations. To this end, the equations of motion, the normal contact problems on tooth flanks and the Reynolds equation for hydrodynamic bearings are simultaneously solved by combining a time-step integration scheme, a Newton-Raphson procedure and a normal contact algorithm. Finally, the importance of gear-bearing 
dynamic interactions and the interest of non-linear models for journal bearings are discussed.

\section{NOMENCLATURE}

$(\vec{s}, \vec{t}, \vec{z})$ : frame of reference ( $\vec{s}$ is along the horizontal center line, $\vec{z}$ is in the axial direction, see figure 1)

$(\vec{x}, \vec{y}, \vec{z})$ : cartesian local frame of the bearing

$(\vec{r}, \vec{q}, \vec{z}):$ polar local frame of the bearing

$\omega$ : rotation speed (ras/s)

$C$ : radial clearance

$\mathcal{E}:$ eccentricity ratio (varies between 0 and 1$)$

$\phi$ : attitude angle (rad)

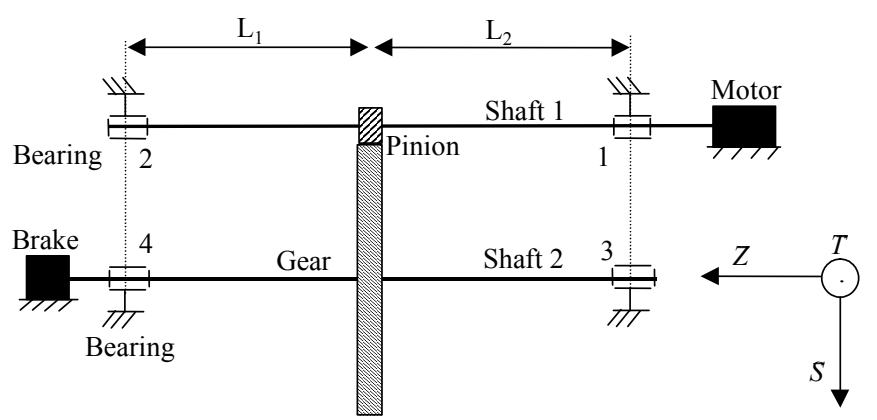

Figure 1 - Sketch of the geared system

\section{1 - DESCRIPTION OF THE MODEL \\ 1-1 Shaft-gear model}

The dynamic model of single stage transmissions (figure 1) is based on the developments of Velex and Maatar [19] and Ajmi and Velex [16]. Shafts are modeled by classic two-node finite elements with 6 degrees of freedom per node for bending (Timoschenko's beam), torsion and axial displacements. A pinion - gear pair are represented by two 2-node shaft elements connected by lumped stiffnesses which account for contact, tooth and gear body deflections along the contact lines in the base plane (figure 2). An elemental mesh stiffness and an equivalent normal shape deviation are associated with every potential point of contact to simulate actual tooth flank traces and their evolutions with time. Based upon rigid-body kinematics, the lines of contact are translated and all relevant parameters (stiffness and deviations) are re-calculated at each time step of the meshing process. It is assumed that the contacts between mating flanks are line contacts within the theoretical base plane and that tooth friction forces can be neglected compared with normal forces. The normal contact condition at every potential point of contact on the tooth flanks is directly included in the mesh stiffness formulation by canceling the elemental stiffness when the corresponding deflection is negative or nil. The proposed formulation leads to time-varying non-linear mesh stiffness matrices and forcing terms, the latter accounting for tooth shape deviations and mounting errors [16], [19], [23]. The pinion-gear mass matrix is classic since second order terms and gyroscopic components are neglected.

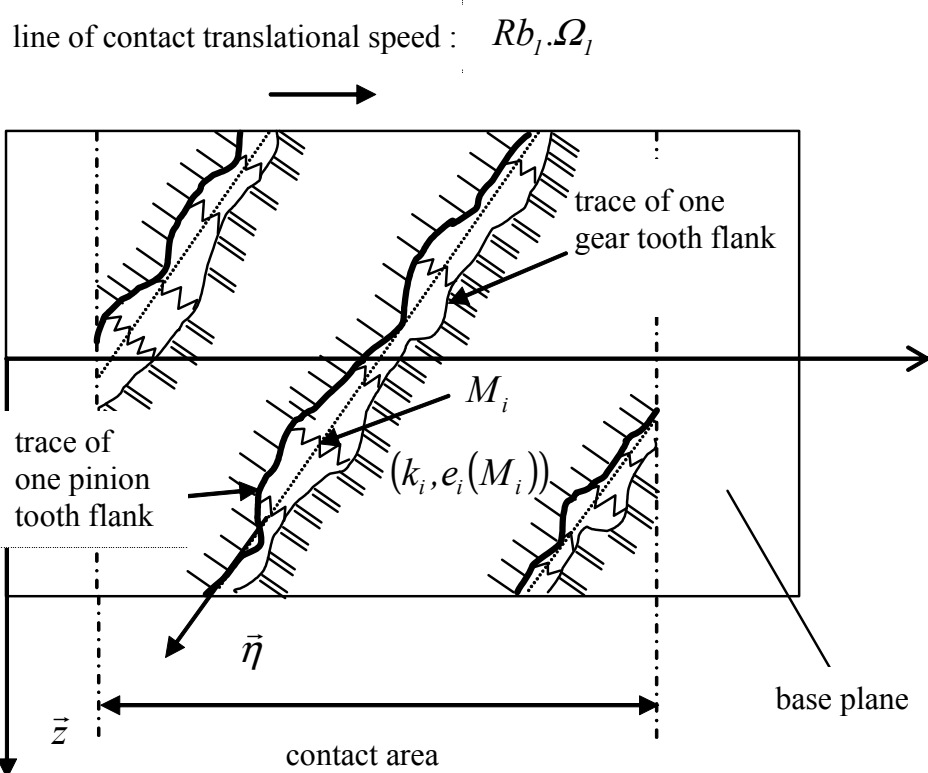

Figure 2 - Model of mesh elasticity and tooth shape deviations

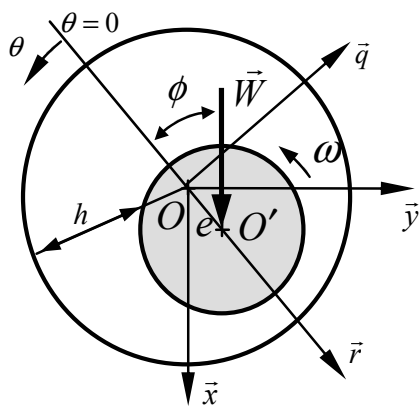

Bearing on shaft 1

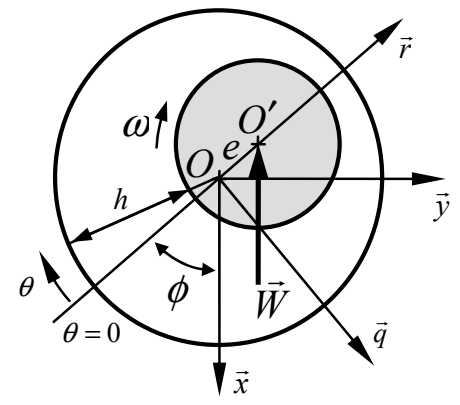

Bearing on shaft 2
Figure 3 - Direction of external load and definition of local frames for the bearings on shaft 1 and 2

\section{1-2 Journal bearing model}

\section{1-2-1 Reynolds equation - Short Bearing} approximation

Figure 3 gives a schematic view of a journal bearing consisting of a fixed journal of radius $R$, length $L$ and of a rotating shaft of radius $R_{s}$, with $C=R-R_{s}$ being the radial clearance. At constant speed $\omega$ and under a constant load $W$, the shaft center $O^{\prime}$ keeps a fixed position in the bearing 
defined by the constant eccentricity $e_{0}$ and attitude angle $\phi_{0}$ whereas, for dynamic conditions, it follows an orbit within the journal clearance characterized by a time-dependent eccentricity $e$ and attitude angle $\phi$. The position of the shaft center with respect to the bearing center $O$ can be described either by its Cartesian co-ordinates in the frame $(\vec{x}, \vec{y})$

$$
\overrightarrow{O O^{\prime}}=x \vec{x}+y \vec{y}=e \cos \phi \vec{x}+e \sin \phi \vec{y}
$$

or its local (or polar) co-ordinates in the frame $(\vec{r}, \vec{q})$

$$
\overrightarrow{O O^{\prime}}=e \vec{r} \quad \phi=(\vec{x}, \vec{r})
$$

Introducing the angular co-ordinate $\theta$ whose origin is on the axis $\vec{r}$, the lubricant film thickness is given as:

$$
h=C(1+\varepsilon \cos \theta)
$$

where the eccentricity ratio $\varepsilon=e / C$ varies between 0 and 1 .

Assuming an isothermal, laminar flow of an iso-viscous incompressible fluid, the behavior of the lubricant film is governed by the Reynolds equation [2]. For the sake of simplicity, the short bearing approximation is introduced, i.e., the width-to-diameter ratio $L / D$ is supposed to be small, which leads to the following Reynolds equation for dynamic conditions:

$$
\frac{\partial}{\partial z}\left[\frac{h^{3}}{\mu} \frac{\partial p}{\partial z}\right]=6\left[(\omega-2 \dot{\phi}) \frac{d h}{d \theta}+2 C \dot{\varepsilon} \cos \theta\right]
$$

Using the boundary conditions $p(\theta, z= \pm L / 2)=0$, Equation (4) can be integrated and the hydrodynamic pressure field is expressed as:

$$
p(\theta, z)=-\frac{3 \mu}{C^{2}}\left(z^{2}-\frac{L^{2}}{4}\right) \frac{(\omega-2 \dot{\phi}) \varepsilon \sin \theta-2 \dot{\varepsilon} \cos \theta}{(1+\varepsilon \cos \theta)^{3}}
$$

The hydrodynamic force $F_{b}$ is obtained by integration of $p(\theta, z)$ for $\theta \in[0,2 \pi]$ and $z \in[-L / 2, L / 2]$ using the Gümbel boundary conditions which discard negative pressures from the force integral [10].

\section{1-2-1 Steady-state solution}

The solution for steady-state conditions can be deduced from (5) by setting the time-varying perturbations $\dot{\varepsilon}$ and $\dot{\phi}$ to zero. The associated hydrodynamic bearing force integration is straightforward and gives

$$
F_{b}\left(\varepsilon_{0}\right)=\mu L R \omega\left(\frac{L}{D}\right)^{2}\left(\frac{R}{C}\right)^{2} \frac{\varepsilon_{0}}{\left(1-\varepsilon_{0}^{2}\right)^{2}} \sqrt{16 \varepsilon_{0}{ }^{2}+\pi^{2}\left(1-\varepsilon_{0}{ }^{2}\right)}
$$

with the attitude angle being defined as

$$
\tan \phi_{0}=\frac{\pi}{4} \frac{\sqrt{1-\varepsilon_{0}^{2}}}{\varepsilon_{0}}
$$

The steady-state position and bearing force depend on $\varepsilon_{0}$. This is derived from the static equilibrium between the hydrodynamic reaction generated by the bearing and the external force $W_{0}$ imposed by the transmitted torques and transferred to the bearings by the pinion and the gear, i.e.,

$$
F_{b}\left(\varepsilon_{0}\right)=W_{0}
$$

This equation is non-linear and it is solved by a dichotomy scheme. In turn, the eccentricity of the shaft in the journal modifies the pinion-gear center distance slightly and consequently, the gear mesh stiffness function and excitations.

\section{1-2-1 Dynamic characteristics}

Denoting $\left(x_{0}, y_{0}\right)$, the shaft center co-ordinates in steady-state conditions and $(\Delta x, \Delta y)$, the corresponding timedependent dynamic perturbations, the actual position of the shaft center is defined as:

$$
\begin{aligned}
\overrightarrow{O O^{\prime}} & =\left(x_{0}+\Delta x\right) \vec{x}+\left(y_{0}+\Delta y\right) \vec{y} \\
& =\left(C \varepsilon_{0} \cos \phi_{0}+\Delta x\right) \vec{x}+\left(C \varepsilon_{0} \sin \phi_{0}+\Delta y\right) \vec{y}
\end{aligned}
$$

From which, the dynamic parameters $\mathcal{E}, \phi$, and their timederivatives $\dot{\mathcal{E}}$ and $\dot{\phi}$ are deduced as:

$\varepsilon=\frac{\sqrt{\left(C \varepsilon_{0} \cos \phi_{0}+\Delta x\right)^{2}+\left(C \varepsilon_{0} \sin \phi_{0}+\Delta y\right)^{2}}}{C}$

$\cos \phi=\frac{C \varepsilon_{0} \cos \phi_{0}+\Delta x}{\sqrt{\left(C \varepsilon_{0} \cos \phi_{0}+\Delta x\right)^{2}+\left(C \varepsilon_{0} \sin \phi_{0}+\Delta y\right)^{2}}}$

$\dot{\varepsilon}=\frac{\partial \varepsilon}{\partial t}=\frac{\left(C \varepsilon_{0} \cos \phi_{0}+\Delta x\right) \Delta \dot{x}+\left(C \varepsilon_{0} \sin \phi_{0}+\Delta y\right) \Delta \dot{y}}{C \sqrt{\left(C \varepsilon_{0} \cos \phi_{0}+\Delta x\right)^{2}+\left(C \varepsilon_{0} \sin \phi_{0}+\Delta y\right)^{2}}}$

$\dot{\phi}=\frac{\partial \phi}{\partial t}=\frac{-\Delta \dot{x} \varepsilon+\left(C \varepsilon_{0} \cos \phi_{0}+\Delta x\right) \dot{\varepsilon}}{\varepsilon\left(C \varepsilon_{0} \sin \phi_{0}+\Delta y\right)}$

\section{2 - DYNAMIC BEHAVIOR OF THE GEAR-BEARING ASSEMBLY}

2-1 Equations of motion

The assembly of all the elemental matrices and forcing term vectors leads to the following system of equations in the frame $(\vec{s}, \vec{t}, \vec{z})$ relative to the structure

$[M]\{\ddot{X}\}+[C]\{\dot{X}\}+[K(t, X)]\{X\}=\{F(t, X)\}+\left\{F_{b}(X, \dot{X})\right\}$

where 
$M$ and $C$ are the global constant mass and damping matrices $X, \dot{X}, \ddot{X}$ are the degree-of-freedom, velocity and acceleration vectors

$K(t, X)$ is the global stiffness matrix of the system, $K(t, X)=K_{\text {shaft }}+K_{\text {gear }}(t, X)$ with

$K_{\text {shaft }}$ : constant global stiffness matrix of the shafts

$K_{\text {gear }}(t, X)$ : global stiffness matrix of the gear which is time-dependant because of the contact length evolution on the base plane and potentially non-linear because of the interaction between the degrees of freedom, tooth deviations and the instantaneous contact extent (Velex and Maatar, [19])

$F(t, X)=F_{0}(t)+F_{\text {gear }}(t, X)$ with

$F_{0}(t)$ : external load vector (input and output torques, mass unbalance, ...)

$F_{\text {gear }}(t, X)$ : embodies the inertial effects caused by unsteady rotations (associated with no-load transmission error) and the contributions of geometrical errors and tooth shape deviations (pitch errors, tooth modifications ....) [19]

$F_{b}(X, \dot{X})$ are the hydrodynamic forces produced by the bearings which are opposing the motions of the shaft as described in section 2 .

If the inertia center of the shaft is different from its geometrical center, then mass imbalance forces are embedded in the external load vector $F_{0}(t)$. In the frame $(\vec{s}, \vec{t}, \vec{z})$, these forces read

$$
F_{m i}=\left\{\begin{array}{c}
F_{m i X} \\
F_{m i Y} \\
0
\end{array}\right\}=\left\{\begin{array}{c}
M e_{m i} \omega^{2} \cos (\omega t) \\
M e_{m i} \omega^{2} \sin (\omega t) \\
0
\end{array}\right\}
$$

for each node of the shaft. In this expression, $M$ is the mass of the shaft plus the pinion or gear and $e_{m i}$ represents the distance between the inertia and geometrical centers of the shaft.

In the proposed formulation (11), the contributions of bearings appear as external forces to the system following the original approach of Abdul-Wahed [27] in his study of the nonlinear behavior of rigid shafts supported by hydrodynamic bearings. The system of equations (11) is non-linear because the hydrodynamic forces $F_{b}(X, \dot{X})$ depend on the position $X$ and on the velocity $\dot{X}$, and because of the contact conditions between the gear teeth. The resolution requires a complex procedure combining several iterative schemes and a time-step integration process as described in Section $3-3$, which will be referred to as non-linear analysis. The solution technique can be significantly simplified by assuming small displacements in the vicinity of the static positions, i.e., using the linear analysis which is probably no longer suited to the case of significant dynamic loads or mass imbalances. Both kinds of analyses, linear and non-linear, are detailed in the following section.

\section{2-2 Linear analysis}

Using a first order expansion in the vicinity of the static solution $X_{0}$ leads to the following dynamic bearing force vectors:

$$
F_{b}(X, \dot{X})=\left\{F_{b 0}\right\}-[K]_{X Y}\{\Delta X\}-[C]_{X Y}\{\Delta \dot{X}\}
$$

where $F_{b 0}$ is obtained by (6), $\Delta X=X-X_{0},[K]_{X Y}$ and $[C]_{X Y}$ represent the stiffness and damping matrices due to the lubricant film.

For short bearings, and applying Gümbel's conditions, the expressions of $[K]$ and $[C]$ are easier to obtain in the local frame $(\vec{r}, \vec{q})$ of the bearing. According to Frêne et al. [10], they read

$$
\begin{aligned}
& {[K]_{r q}=\frac{W_{0}}{C}\left[\begin{array}{ll}
A_{r r} & A_{r q} \\
A_{q r} & A_{q q}
\end{array}\right] \quad[C]_{r q}=\frac{W_{0}}{C \omega}\left[\begin{array}{ll}
B_{r r} & B_{r q} \\
B_{q r} & B_{q q}
\end{array}\right]} \\
& A_{r r}=\frac{8\left(1+\varepsilon_{0}^{2}\right)}{1-\varepsilon_{0}^{2}} f\left(\varepsilon_{0}\right) \quad A_{r q}=\frac{\pi}{\varepsilon_{0}} \sqrt{1-\varepsilon_{0}^{2}} f\left(\varepsilon_{0}\right) \\
& A_{q r}=\frac{-\pi\left(1+2 \varepsilon_{0}^{2}\right)}{\varepsilon_{0} \sqrt{1-\varepsilon_{0}^{2}}} f\left(\varepsilon_{0}\right) \quad A_{q q}=4 f\left(\varepsilon_{0}\right) \\
& B_{r r}=-2 A_{q r} \quad B_{q q}=2 A_{r q} \quad B_{r q}=B_{q r}=-2 A_{q q} \\
& f\left(\varepsilon_{0}\right)=\frac{1}{\sqrt{16 \varepsilon_{0}^{2}+\pi^{2}\left(1-\varepsilon_{0}^{2}\right)}}
\end{aligned}
$$

where $W_{0}$ is the static load generated by the meshing and applied to the bearing. The coefficients $A_{i j}$ and $B_{i j}$ depend on $\mathcal{E}_{0}$ only, which characterizes the steady-state position, such that $[K]=\left[K\left(\varepsilon_{0}\right)\right]$ and $[C]=\left[C\left(\varepsilon_{0}\right)\right]$.

The matrices $[K]_{r q}$ and $[C]_{r q}$ can be transferred from the local frame $(\vec{r}, \vec{q})$ into the Cartesian frame $(\vec{x}, \vec{y})$ by

$$
\begin{aligned}
& {\left[K\left(\varepsilon_{0}\right)\right]_{x y}=[P]\left[K\left(\varepsilon_{0}\right)\right]_{r q}[P]^{-1}} \\
& {\left[C\left(\varepsilon_{0}\right)\right]_{x y}=[P]\left[C\left(\varepsilon_{0}\right)\right]_{r q}[P]^{-1}}
\end{aligned}
$$

where 


$$
[P]=\left[\begin{array}{cc}
\cos \phi_{0} & -\sin \phi_{0} \\
\sin \phi_{0} & \cos \phi_{0}
\end{array}\right]
$$

for bearings on the input (pinion) shaft and

$$
[P]=\left[\begin{array}{cc}
-\cos \phi_{0} & \sin \phi_{0} \\
\sin \phi_{0} & \cos \phi_{0}
\end{array}\right]
$$

for bearings on the output (gear) shaft, with the attitude angle $\phi_{0}$ obtained by (7).

Finally, the matrices $[K]_{X Y}$ and $[C]_{X Y}$ in Equation (13) are obtained by applying a second change of basis, from $(\vec{x}, \vec{y}, \vec{z})$ to $(\vec{s}, \vec{t}, \vec{z})$

$$
\begin{aligned}
& {\left[K\left(\varepsilon_{0}\right)\right]_{X Y}=[Q]\left[K\left(\varepsilon_{0}\right)\right]_{x y}[Q]^{-1}} \\
& {\left[C\left(\varepsilon_{0}\right)\right]_{X Y}=[Q]\left[C\left(\varepsilon_{0}\right)\right]_{x y}[Q]^{-1}}
\end{aligned}
$$

with

$$
[Q]=\left[\begin{array}{cc}
-\sin \alpha & \cos \alpha \\
-\cos \alpha & -\sin \alpha
\end{array}\right]
$$

for all bearings, where $\alpha$ is the pressure angle.

Replacing the expression (13) of $F_{b}(X, \dot{X})$ into the equations of motion (11) along with the expressions of $\Delta X$ and $\Delta \dot{X}$, one obtains the linear system of equations in the frame $(\vec{s}, \vec{t}, \vec{z})$

$$
\begin{aligned}
{[M]\{\ddot{X}\}+\left[C_{0}\right]\{\dot{X}\}+\left[K_{0}\right]\{X\} } & = \\
\{F(t, X)\}+\left\{F_{b 0}\right\} & +\left[K\left(\varepsilon_{0}\right)\right]_{X Y}\left\{X_{0}\right\}
\end{aligned}
$$

where

$$
\begin{aligned}
& {\left[C_{0}\right]=[C]+\left[C\left(\varepsilon_{0}\right)\right]_{X Y}} \\
& {\left[K_{0}\right]=[K]_{\text {shaft }}+[K]_{\text {gear }}+\left[K\left(\varepsilon_{0}\right)\right]_{X Y}}
\end{aligned}
$$

The differential system (20) is solved by the implicit Newmark time-step integration scheme combined with a normal contact algorithm which verifies that all contact forces on the teeth are positive and no contact deflections occur outside the contact area [19].

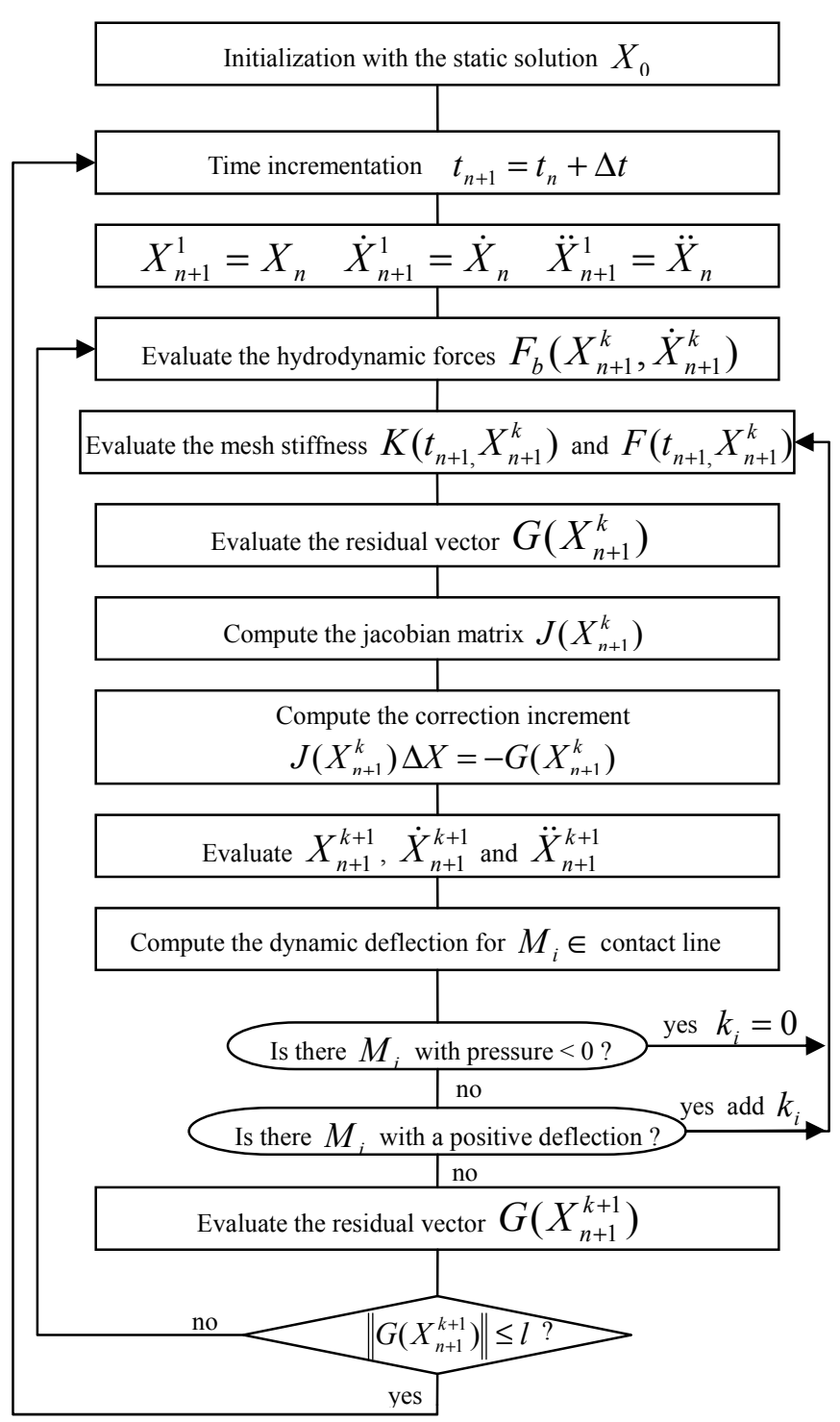

Table 1 - Iterative procedure

\section{2-3 Non-linear analysis}

Because of the assumption of small perturbations, the linear theory cannot account for large dynamic loads. Solving the complete non-linear problem requires the Reynolds equation in dynamic regime, the contact conditions on the teeth and the equations of motion to be dealt with simultaneously. In this case, the hydrodynamic forces $F_{b}(X, \dot{X})$ are obtained by numerical integration of the pressure field given by (5) as 


$$
F_{b}=\left\{\begin{array}{l}
F_{b r} \\
F_{b q}
\end{array}=\left\{\begin{array}{l}
\iint p(\theta, z) \cos \theta R d \theta d z \\
\iint p(\theta, z) \sin \theta R d \theta d z
\end{array}\right.\right.
$$

with $z \in[-L / 2, L / 2]$ and $\theta \in[0,2 \pi]$.

As for the linear approach, Gümbel's conditions are obtained by considering only the positive values of $p(\theta, z)$. The components of $F_{b}(X, \dot{X})$ in frames $(\vec{x}, \vec{y}, \vec{z})$ and $(\vec{s}, \vec{t}, \vec{z})$ are respectively given by

$$
\begin{aligned}
& \left\{\begin{array}{l}
F_{b x} \\
F_{b y}
\end{array}\right\}=[P]\left\{\begin{array}{l}
F_{b r} \\
F_{b q}
\end{array}\right\} \\
& \left\{\begin{array}{l}
F_{b X} \\
F_{b Y}
\end{array}\right\}=[Q]\left\{\begin{array}{l}
F_{b x} \\
F_{b y}
\end{array}\right\}
\end{aligned}
$$

where $[P]$ and $[Q]$ are the matrices in (16), (17) and (19)

The non-linear equations (11) are solved by combining the Newmark time integration scheme with the Newton-Raphson incremental-iterative algorithm, and with an iterative process aimed at updating the dynamic characteristics of the meshing process (Table 1).

\section{3 - NUMERICAL RESULTS}

The gear, shaft and bearing data used in the numerical simulations are given in Tables 2 to 4 . A unique modal damping factor of 0.03 has been used for all the numerical simulations and the time increment $\Delta t$ was set to $1 / 32$ th of the mesh period. All simulations were performed over 256 mesh periods, i.e. 8192 time increments, which correspond approximately to 10 pinion revolutions.

\section{3-1 Gear-bearing interactions}

A first simulation was performed with an input (pinion) speed $\omega=700 \mathrm{rad} / \mathrm{s}$, an input torque $C=200 \mathrm{~N}$.m and the mass imbalance forces in (12) were computed with $e_{m i}=0.5 \mathrm{~mm}$. The corresponding transient motion of the shaft center in bearing 1 (input shaft) is plotted in Figure 4a. The motion, composed of 10 loops corresponding to the 10 pinion revolutions, becomes stable after the transient oscillations on the first orbits have disappeared. The last calculated orbit is shown in Figure $4 \mathrm{~b}$ which shows the 26 oscillations associated with the mesh period and demonstrates the interaction between the gears and the bearings. The norm of the hydrodynamic forces over the last orbit, i.e. the last 256 mesh periods, of the same bearing is plotted in Figure 5. The low-frequency excitation seems prevalent but, as in the previous example, the mesh frequency components appear in the time signal superimposed on the basic once-per-revolution period related to mass imbalance.

\begin{tabular}{|c|c|c|}
\hline & Pinion & Gear \\
\hline Number of teeth & 26 & 157 \\
\hline Face width $(\mathrm{mm})$ & 50 & 40 \\
\hline Helix angle $\left(^{\circ}\right)$ & \multicolumn{2}{|c|}{0} \\
\hline Module $(\mathrm{mm})$ & \multicolumn{2}{|c|}{40} \\
\hline Pressure angle $\alpha\left(^{\circ}\right)$ & 1. & 1. \\
\hline Dedundum coefficient & 1.4 & 1.4 \\
\hline Addendum coefficient & 0.16 & -0.16 \\
\hline Profile shift coefficient & \multicolumn{2}{|c|}{366} \\
\hline Center distance $(\mathrm{mm})$ & 2 & 74 \\
\hline Mass $(\mathrm{kg})$ & & \\
\hline
\end{tabular}

Table 2 - Gear data

\begin{tabular}{|c|c|c|}
\hline & Pinion shaft & Gear shaft \\
\hline Outer diameter $(\mathrm{mm})$ & 70 & 90 \\
\hline Inner diameter $(\mathrm{mm})$ & 30 & 30 \\
\hline Shaft length $(\mathrm{mm})$ & \multicolumn{2}{|c|}{$L_{1}=L_{2}=160$} \\
\hline Young modulus $\left(\mathrm{N} / \mathrm{m}^{2}\right)$ & \multicolumn{2}{|c|}{$2.1 .10^{11}$} \\
\hline Density $\left(\mathrm{kg} / \mathrm{m}^{3}\right)$ & 7800 \\
\hline
\end{tabular}

Table 3 - Shaft data

\begin{tabular}{|c|c|c|}
\hline & $\begin{array}{c}\text { Bearings 1 and 2 } \\
\text { Pinion shaft }\end{array}$ & $\begin{array}{c}\text { Bearings 3 and 4 } \\
\text { (gear shaft) }\end{array}$ \\
\hline Diameter $(\mathrm{mm})$ & 70 & 90 \\
\hline Length $(\mathrm{mm})$ & 14 & 18 \\
\hline Radial clearance $(\mu \mathrm{m})$ & 150 & 110 \\
\hline
\end{tabular}

Table 4 - Bearing data 

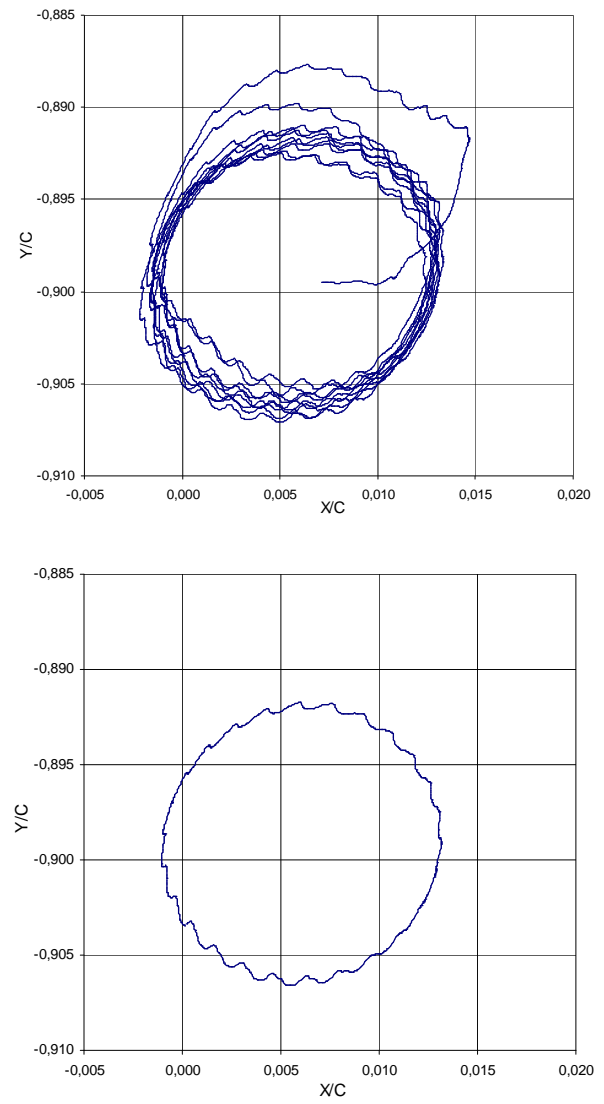

Figure 4-a) Transient motion of the shaft center of bearing 1 and $b$ ) last calculated orbit

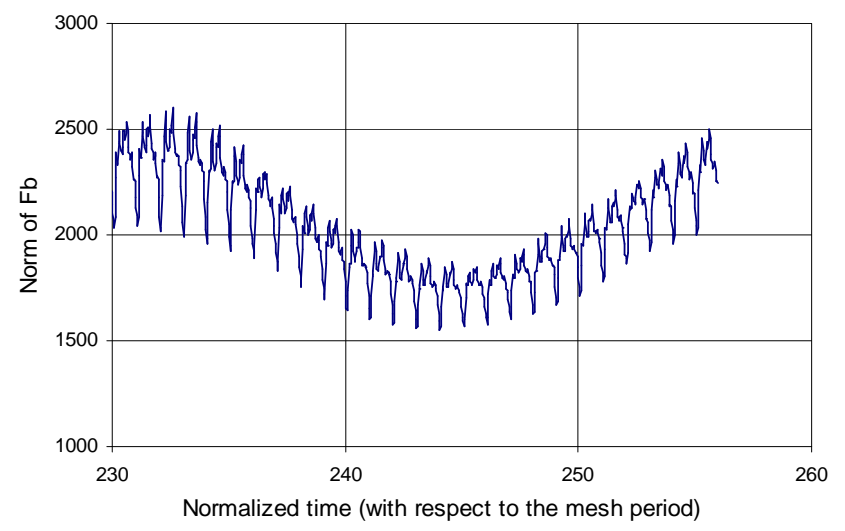

Figure 5 - Norm of the hydrodynamic forces $F_{b}$ in bearing 1 for the last orbit

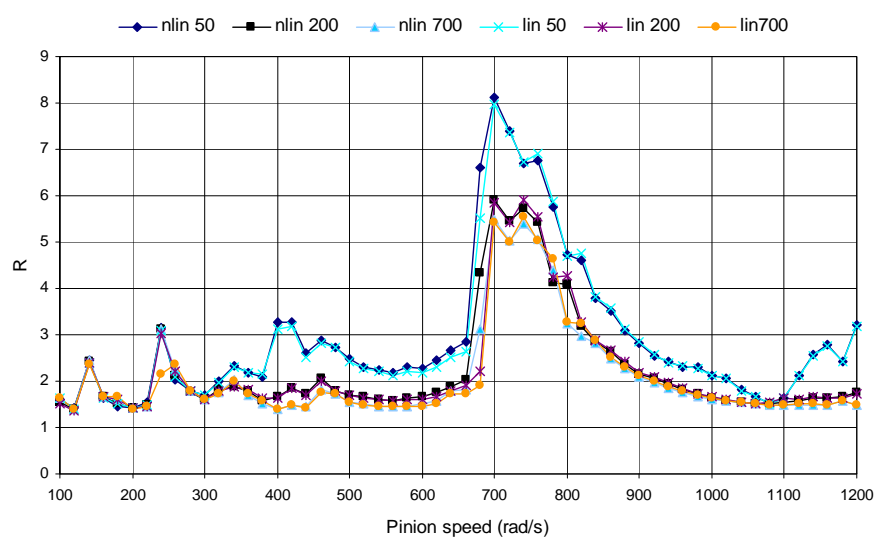

Figure 6 - Maximum dynamic-to-maximum static mesh load ratio for different input torques

\section{3-2 Comparison of the linear and the non-linear theories}

Dynamic tooth loading is characterized by considering the dynamic tooth load factor $R$ defined as the ratio of the maximum dynamic mesh force to the maximum static one. Figure 6 represents the evolutions of $R$ versus the pinion speed calculated for various loads and using different solution techniques. The solutions obtained by the linear and non-linear methods are very close and are dominated by amplitude jumps and shocks at the major tooth critical frequency. It can also be observed that dynamic amplifications are reduced when the transmitted torque is increased.

Considering bearing forces, the results on the pinion shaft (Figure 7) reveal that, here again, the linear and non-linear theories lead to very similar response curves with slightly larger differences as the transmitted load increases. The situation is different on the gear shaft, as illustrated in Figure 8, for which the non-linear and linear results deviate significantly as either speed or load increases. This discrepancy is apparently caused by the larger imbalance on the gear. This observation is confirmed by the bearing force plots in Figure 9, obtained for three imbalance amplitudes $\left(e_{m i}=0 \mathrm{~mm}, e_{m i}=0.5 \mathrm{~mm}\right.$ and $\left.e_{m i}=1 \mathrm{~mm}\right)$, which indicate that larger dynamic forces make non-linear modeling necessary.

On the other hand, dynamic tooth loads appear as moderately sensitive to imbalance, as illustrated in Figure 10, and, in contrast to bearing forces, the linear and non-linear results remain very close whatever the imbalance amplitude. The final set of results in Figures 11 and 12, shows, for two imbalance amplitudes $\left(e_{m i}=0.5 \mathrm{~mm}\right.$ and $\left.e_{m i}=1 \mathrm{~mm}\right)$, the trajectories of the pinion shaft in its bearings for a pinion speed ranging from 100 to $1200 \mathrm{rad} / \mathrm{s}$. The previous conclusions about the role of dynamic force amplitudes on shaft-bearing interactions are confirmed and suggest that linear theories might not be suited for accurate vibration transfer analysis. 

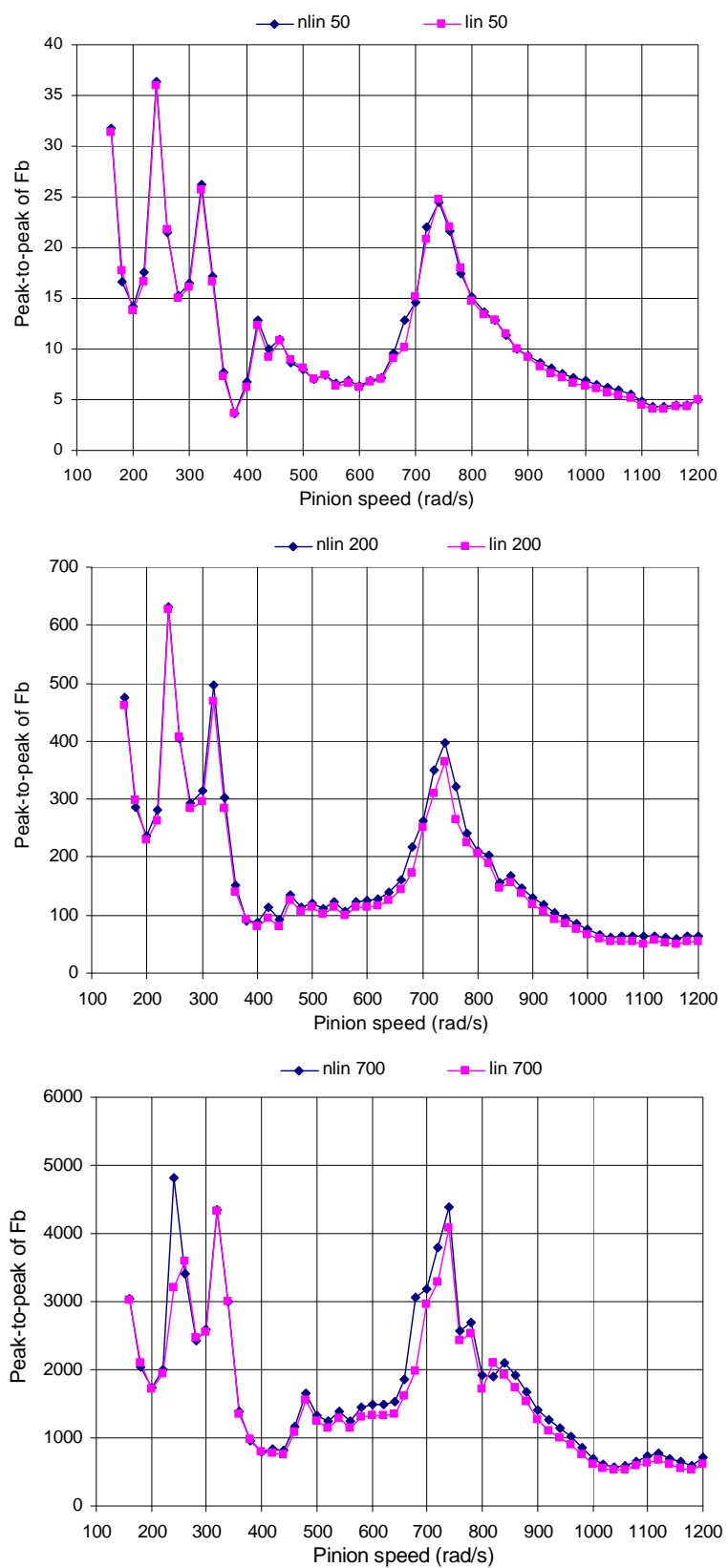

Figure 7 - Peak-to-peak of the hydrodynamic load $F_{b}$ in bearing 1 for different input torques
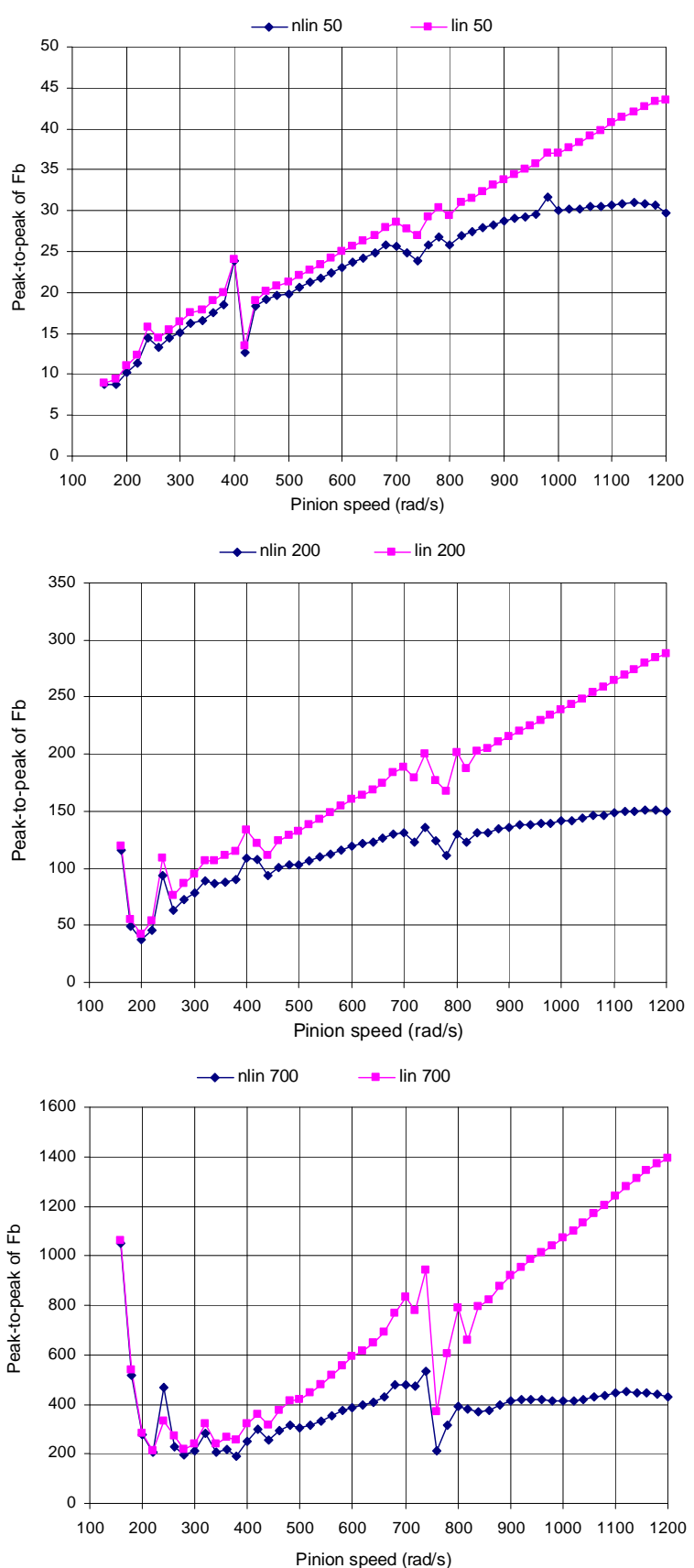

Figure 8 - Peak-to-peak of the hydrodynamic load $F_{b}$ in bearing 3 for different input torques 

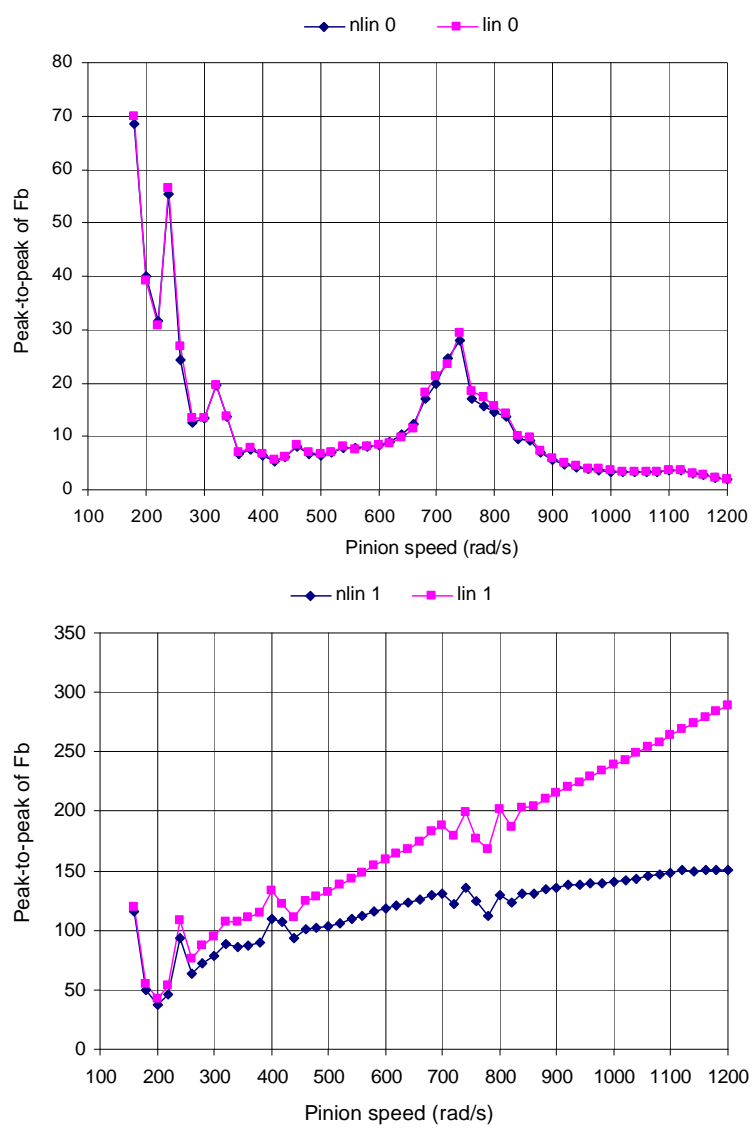

$\rightarrow$ - nlin $2-\operatorname{lin} 2$

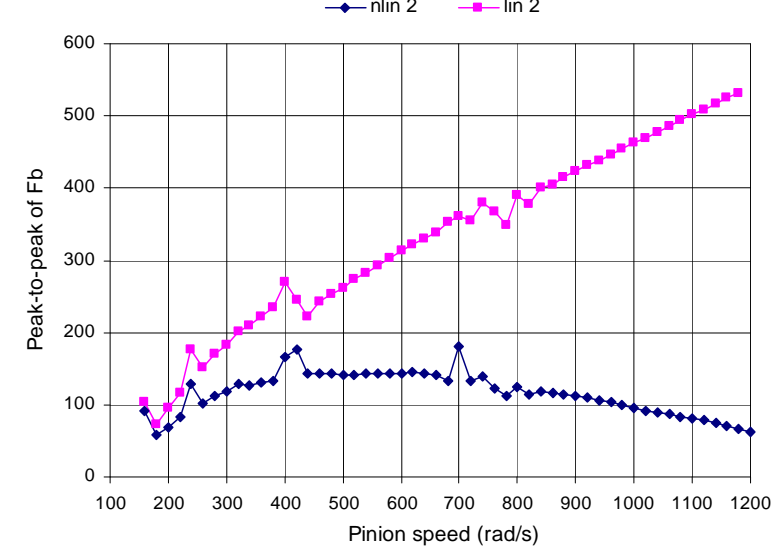

Figure 9 - Peak-to-peak of the hydrodynamic load $F_{b}$ in bearing 3 for different values of the mass imbalance

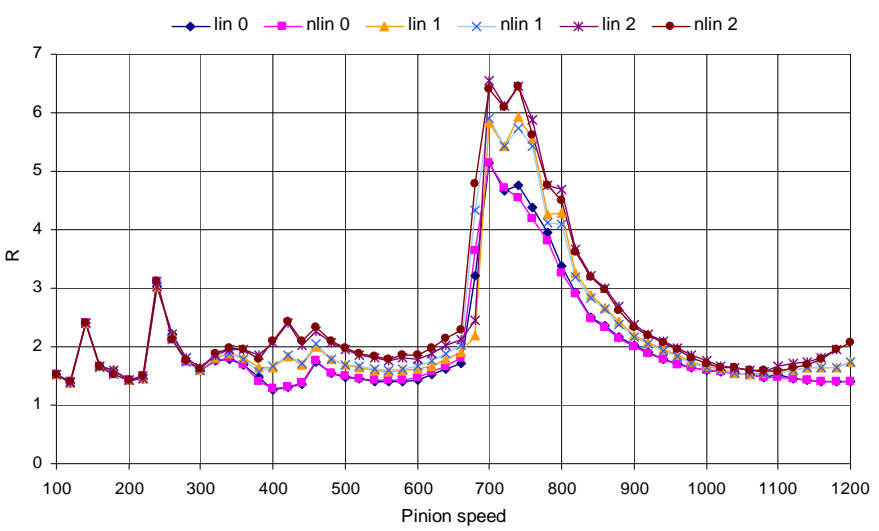

Figure 10 - Maximum dynamic-to-maximum static mesh load ratio for different amplitudes of the mass imbalance
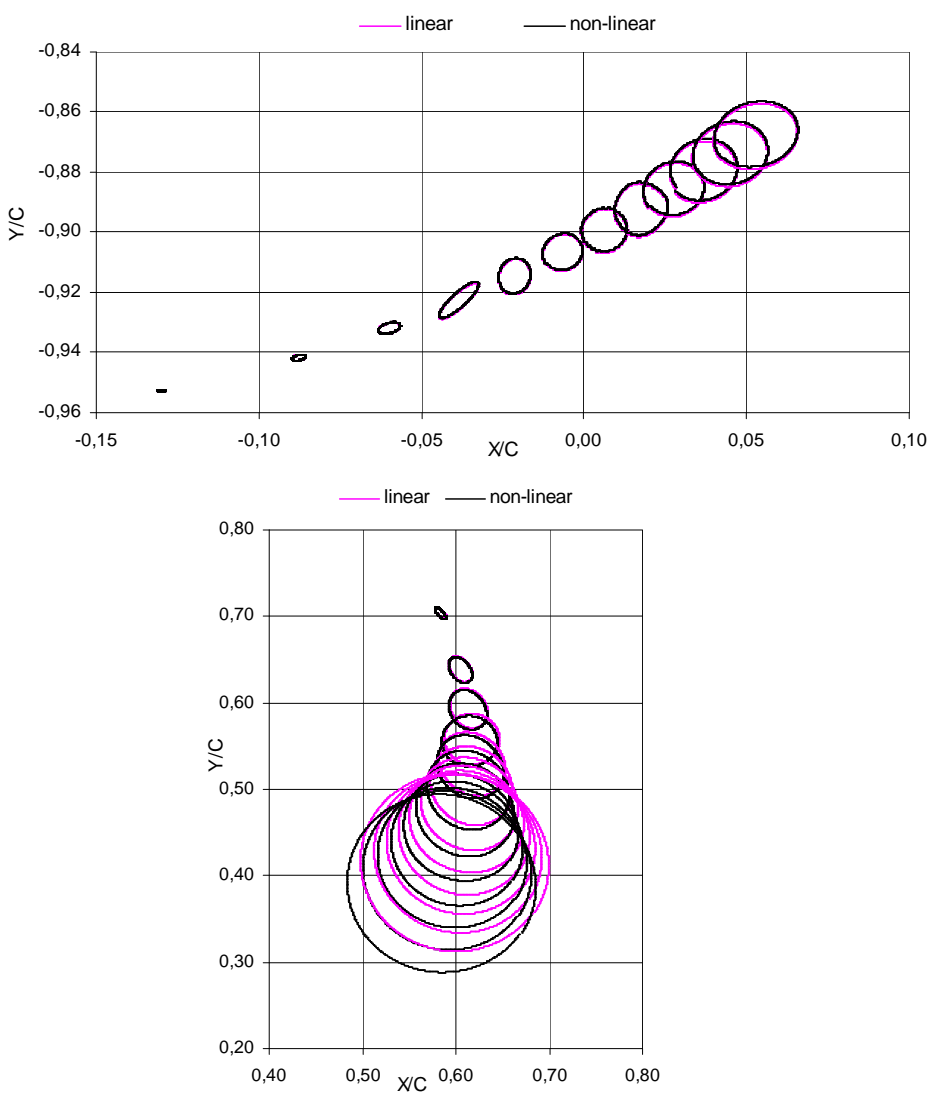

Figure 11 - Orbits of bearings 1 and 3 for values of the input speed from $100 \mathrm{rad} / \mathrm{s}$ (smallest orbit) up to 1200 $\mathrm{rad} / \mathrm{s}$ (largest orbit) obtained by the linear and non-linear theory - Mass imbalance corresponding to case 1 

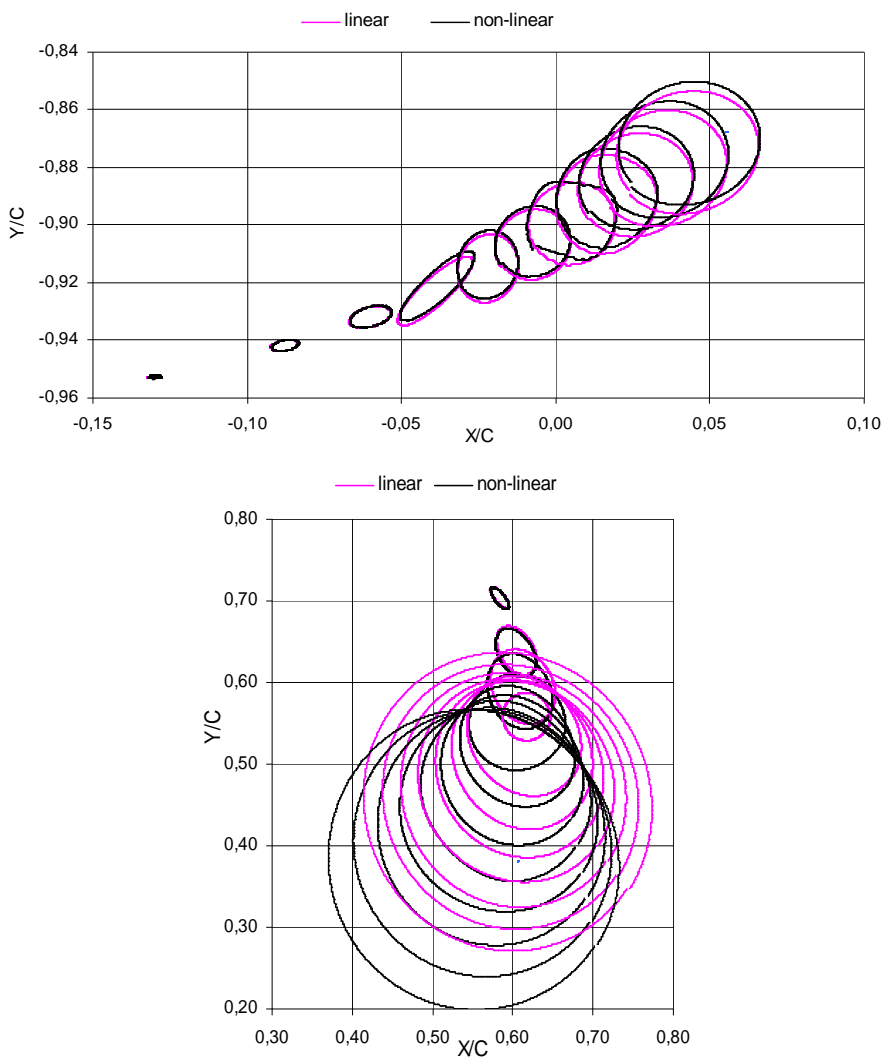

Figure 12 - Orbits of bearings 1 and 3 for values of the input speed from $100 \mathrm{rad} / \mathrm{s}$ (smallest orbit) up to 1200 $\mathrm{rad} / \mathrm{s}$ (largest orbit) obtained by the linear and non-linear theory - Mass imbalance corresponding to case 2

\section{CONCLUSION}

This paper presents a model of gear-shaft-bearing systems which accounts for various contact non-linearities and couplings. The state equations are solved by an original technique which combines a Newmark scheme, a NewtonRaphson procedure for bearing non-linearities, and a unilateral contact algorithm which deals with the contact problem on gear teeth. The proposed theory is applied to a simplified F.E. model of a single-stage spur gear system with 2 shafts and 4 bearings.

From the numerical examples, the following observations can be made:

i) for accurate predictions of vibration transfer through the bearings, bearing non-linear behavior has to be taken into account in the case of large dynamic forces,

ii) mesh excitations appear in the dynamic bearing response although bearing force amplitudes are usually dominated by imbalance,

iii) dynamic tooth load sensitivity to once-per-revolution excitations seems very limited.
The present study is part of a research program on dynamic couplings in geared systems and is clearly approximate in nature since it is based on the short-bearing theory which limits the practical range of applications. Further work is under way to account for the influence of helical gears, different bearing technologies and flexible mounts.

\section{REFERENCES}

[1] HOLMES, R., 1960, ' The Vibration of a Rigid Shaft in Short Sleeve Bearings', Journal Mech. Eng. Sc., vol. 2, pp. 337-341.

[2] DOWSON, D. , 1962, 'A Generalized Reynolds Equation for Film Fluid Lubrication', Int. Journal Mech. Sc., vol. 4, pp. 159-170.

[3] LUND, J. W., 1965, 'The Stability of an Elastic Rotor in Journal Bearings with Flexible Damped Supports', ASME, Journal of Applied Mechanics, pp. 911-918.

[4] BOOKER, J. F., 1965, 'Dynamically Loaded Journal Bearings: Mobility Method of Solution', ASME, Journal of Basic Engineering, vol. 4, pp. 537-

[5] RHODE, S.M. and LI, D.F., 1980, 'A Generalized ShortBearing Theory', ASME, Journal of Lubrication Technology, vol. 102 , pp. 278-282.

[6] FERRON, J. , FRENE, J. and BONCOMPAIN, R. , 1983, ‘ A Study of the Thermodynamic Performance of a Plain Journal Bearing - Comparisons between Theory and Experiments', ASME, Journal of Lubrication Technology, vol. 105, pp. 422428.

[7] FANTINO, B. and FRENE, J. , 1985, ' Comparison of Dynamic Behavior of Elastic Connecting Rod Bearing in Both Petrol and Diesel Engines', ASME, Journal of Tribology, vol. 107, pp 87-91.

[8] CAMERON, A., 1966, 'The Principles of Lubrication', Longmans.

[9] PINKUS, O. and STERNLICHT, B. , 1971, 'Theory of Hydrodynamic Lubrication', Mc Graw-Hill, New-York.

[10] FRENE, J. , NICOLAS, D. , DEGUEURCE, B. , BERTHE, D. and GODET, M., 1997, 'Hydrodynamic Lubrication - Bearings and Thrust Bearings', Elsevier, Tribology Series, 33, 470 p.

[11] ÖZGÜVEN H. N. and HOUSER D. R. , 1988, 'Mathematical models used in gear dynamics. A review', Journal of Sound and Vibration, vol. 121, pp. 383-411. 
[12] VELEX, P. , 1993, 'Modélisation du comportement dynamique des transmissions par engrenages', Chapter 2 of 'Comportement dynamique et acoustique des transmissions par engrenages', CETIM Ed. , pp. 39-95.

[13] BLANKENSHIP, G. W. and SINGH, R. , 1992, 'A comparative study of selected mesh force interface dynamic models', Proc. $6^{\text {th }}$ ASME Power Transmission and Gearing International Conference, Phoenix, pp. 137-146.

[14] BLANKENSHIP G. W. and SINGH, R. , 1995, ' A new gear interface dynamic model to predict multi-dimensional force coupling and excitation', Mechanism and Machine Theory, vol. 30, pp. 43-57.

[15] GREGORY, R. W. , HARRIS, S. L. and MUNRO, R. G. , 1963; 'Dynamic behaviour of spur gears', Proc. ImechE, vol. 178 , pp. 261-266.

[16] M. AJMI and P. VELEX 'A model for simulating the quasi-static and dynamic behaviour of solid wide-faced spur and helical gears', Mechanism and Machine Theory, vol. 40, February 2005, pp. 173-190.

[17] MUNRO, R. W. , 1962, 'The dynamic behaviour of spur gears', PhD Dissertation, Cambridge University.

[18] ÖZGÜVEN H. N. and HOUSER D. R. , 1988, ' Dynamic analysis of high speed gears by using static loaded transmission error', Journal of Sound and Vibration, vol. 125, pp. 71-83.

[19] VELEX, P., MAATAR, M., 1996, A mathematical model for analyzing the influence of shape deviations and mounting errors on gear dynamic behaviour. Journal of Sound and Vibration, Vol. 191, N 5, p. 629-660.

[20] KAHRAMAN A. and SINGH R. , 1990, ' Non-linear dynamics of a spur gear pair', Journal of Sound and Vibration, vol. 142 , pp. 49-75.

[21] KAHRAMAN A. and BLANKENSHIP, G. W. , 1997, 'Experiments on non-linear dynamic behavior of an oscillator with clearance and periodically time-varying parameters', Journal of Applied Mechanics, vol. 64, pp. 217-226.

[22] PARKER, R. G. , VIJAYAKAR, S. M. and IMAJOU, T. , 2000, 'Modeling the non linear vibration of a spur gear pair', Proc. $8^{\text {th }}$ ASME Power Transmission and Gearing International Conference, Baltimore, DETC00/PTG-14434, 10 p.

[23] BAUD, S. and VELEX, P. , 2002, 'Static and dynamic tooth loading in spur and helical geared systems. Experiments and code validation', ASME, Journal of Mechanical Design, vol. 124, pp. 334-346.
[24] HOUPERT, L., 1995, 'Prediction of bearing, gear and housing performances.' Proc. of Rolling Bearing Practice Today seminar, I. Mech. E. London, February, 30 p.

[25] BOURDON, A., RIGAL, J.F., PLAY, D., 1999, 'Static rolling bearing models in a C.A.D. Environment for the study of complex mechanisms: Part I - Rolling bearing model.', ASME, Journal of Tribology, Vol. 121, pp. 205-214.

[26] BOURDON, A., RIGAL, J.F., PLAY, D., 1999, 'Static rolling bearing models in a C.A.D. Environment for the study of complex mechanisms: Part II - Complete Assembly model.', ASME, Journal of Tribology, Vol. 121, pp. 215-223.

[27] ABDUL-WAHED, N. , 1982, ' Comportement Dynamique des Paliers Fluides - Etude Linéaire et Non-Linéaire', Thèse de Doctorat d'Etat es-Sciences, Lyon. 